\title{
Benign Congenital Hypotonia
}

National Cancer Institute

\section{Source}

National Cancer Institute. Benign Congenital Hypotonia. NCI Thesaurus. Code C98840.

Mild hypotonia that usually appears early in infancy and has a favorable outcome. It is not a manifestation of another disorder that may cause hypotonia (e.g., cerebral palsy or muscular dystrophy). 